\title{
18
}

\section{SOCIAL EXCLUSION AND INFORMATION SYSTEMS IN COMMUNITY HEALTHCARE}

\author{
Tony Cornford and Ela Klecun-Dabrowska \\ Department of Information Systems, London School of Economics and Political Science, UK
}

\begin{abstract}
This paper discusses information systems in community development contexts through the perspective of social exclusion. The discussion is situated within a particular geographical community in London and is based on initiatives to address healthcare needs within the context of a connected community initiative. The discussion considers the relation of information systems to social development and processes of inclusion (or exclusion).
\end{abstract}

Keywords: Information systems, community healthcare, social exclusion, digital divide, telehealth.

\section{INTRODUCTION}

Information systems (IS) research is biased towards business usage, serving the needs of late capitalism and focusing on a narrow and untypical sector's consumption of 'leading edge' technologies. There are of course exceptions, for example in literature discussing information systems in development and in the public sector (Avgerou, 2002; Heeks et al., 1999). Within the healthcare sector most attention is given to organisational information systems and to application of ICT to medicine and clinical practice. While some works do discuss community systems they tend to focus on individual projects and their evaluation (Brennan et al., 1997; Gustafson et al., 2001; Sosa-Iudicissa et al., 1997). In contrast, in this paper our aim is to explore how community health information systems might serve communities with high levels of deprivation, drawing from the theory of social exclusion and literature concerned with the relationship between an 
(information) society and the technology at its disposal (Dutton and Peltu, 1996; Kling, 1996).

Social exclusion provides a theoretical stance akin to the discourse of the digital divide, though we suggest that it is more encompassing and sharply focused, looking beyond isolated processes of digital exclusion, to a matrix of interlinked processes that contribute to the exclusion of people and groups within a society or community (Compaine; 2001; Haddon, 2000; Norris, 2001). Such exclusion processes span many mutually influencing levels, from the acts and attitudes of an individual through local contexts and communities to national and global structures (Burchardt et al., 2002).

This paper reports a local study, but the issues it addresses, of the relation of information systems to social development and processes of inclusion (or exclusion), have a wider significance. The study took place within the London Borough of Lewisham and in relation to its needs for health and social care as expressed by local people through discussions and initiatives they engaged in, and by local government bodies and health agencies through their strategies and programmes. The themes we identify aspirations to 'harness' information and communication technology (ICT) to re-model health and social care delivery around patient needs and digital citizenship, and to enhance self-care and processes of community support, are relevant to many other poor or excluded communities in developed and developing countries as they encounter and assess the possibilities of ICTs. Equally, the potential problems such ICT-based services pose have a parallel in myriad other contexts across the developing and developed world. As Phipps (2000: p.64) argues "Applied to enhance access, choices, and social participation, new communications technologies can be a conduit for social inclusion - resting on our societal and strategic choices".

\section{SOCIAL EXCLUSION AND INFORMATION SYSTEMS}

The concept of social exclusion has gained popularity through the 1990s and it is now widely used within academic and political discourse across Europe in discussion of social policy, as well as in developing country contexts as an expression of a lack of civil and social rights (Gore and Figueiredo, 1998; Hills et al., 2002). Burchardt et al. (1999) describe social exclusion as a "contested term", tracing its European, in particular French, origins and contrasting it with the older and cruder concepts of poverty, or deprivation, or the more binary concepts of ghettoization and the underclass developed in American literature (Andersen, 1999). In policy debates the term expresses a dynamic and multifaceted understanding of the unfolding 
circumstances of people, groups or neighbourhoods at the margins of society; 'a short hand term for what can happen when people or areas suffer from a combination of linked problems such as unemployment, poor skills, low incomes, poor housing, high crime environments, bad heath, poverty and family breakdown' (SEU, 1999). Exclusion also features in debates about information society and innovative information systems in the public sector, often in terms of a scenario of information rich and information poor or the digital divide, framed in terms of a lack of ability to access information, including lack of resources or access to technology, and a lack of knowledge or understanding as to what to do with information. Social exclusion perspectives recognise change over time and dynamic processes of inclusion and exclusion at work within society, rather than identifying groups or individuals as being just excluded (or included) (Hills, 1997). Inclusion and exclusion is not absolute or binary but results from multiple circumstances, attitudes and dispositions, as well being relative to the wider society (Atkinson, 1998; Richardson and Grand, 2002). Milbourne (2002) illustrates how processes of exclusion can accrue over time and may lead to a gradual withdrawal from community networks and to decreasing access to social resources. Richardson and LeGrand (2002), based on discussions with focus groups from excluded communities in Britain, propose broad dimensions of exclusion in terms of participation in consumption activity, production activity, political activity and social activity, as well as use of publicly funded and provided services, such as health, education and transport, and of public goods such as a safe environment. Such a multi dimensional framework means that it is necessary to address the question of agency in such processes, as Burchardt et al. (2002) pose it, 'Who is doing the excluding?'. This might be answered in various ways ranging from accounts that focus on institutional structures, discrimination or lack of enforced rights, to seeing those excluded as responsible.

Social exclusion has been reflected in many contemporary health policy initiatives in the UK. 20 years ago the Black Report (DHSS, 1980) documented the way in which health inequalities had survived between the social classes in the UK even after 30 years of a comprehensive National Health Service (NHS) free at the point of delivery, findings confirmed by follow up studies (Whitehead, 1988; Acheson, 1998). The recent UK Government consultative green paper 'Our Healthier Nation' (DOH, 1998), similarly expresses its aim, "To improve the health of the worst off in society and to narrow the health gap" (p.5). Thus social exclusion is identified as both one of the causes and the effects of ill health or disability. Growing out of this perspective has come a strategy for promotion of health information flows within the institutional world of healthcare provision and into the community, with UK initiatives including the web-site, Wired for 
Health (DOH, 1999), and NHSDirect, a nurse-led telephone triage system handling 450,000 calls a month'.

Attention to building stronger information flows within the health sector leads to consideration of the role that ICT might play in processes of inclusion and exclusion in relation to availability and accessibility of health services. Thus it may be connected to distance (which is relative -3 miles in the City can be a very long journey, not least in cultural terms), to time (can a person use a service within their time constraints - for example as a single mother without child care), to mobility (ability to travel to access the services - for example as a disabled person), to cost (even a free service requires time off work), to 'understandibility' (having the language to understand information), to suitability and focus (is the service in some way 'personalised'), and to awareness (is a person aware of services on offer). We also understand that people can be excluded because of their attitudes and values (the agency dimension). All these characteristics are potentially interrelated in processes that reinforce exclusion, but are changeable as a person's or their community's circumstances and resources evolve. We note in particular the close link between individual and community exclusion, not only in terms of geographical constraints, for example lack of local health services or bad transport links, but also in terms of community-based culture, habits and shared attitudes.

Given the desire for an informational response to exclusion, ICTs are often proposed as 'solutions'. For patients, ICT-based services may offer better quality of care, for example improved access through teleconsultation facilities, convenience and cost-savings through local services and up-todate information, better service or better trained and supported personnel able to provide better care (Yach, 1998). Others argue that telecare allows greater flexibility and responsiveness, for example, enabling the elderly to be cared for at home, providing safety, security and health benefits (Coyle et al., 1995; Sixsmith, 2000; Whitten et al., 1998), and a means of interacting in a client-centred manner, promoting patient autonomy through education and improved communication (Warner, 1997). We must also recognise that in the research literature these claims are not well documented (Collins et al., 2000; Hakansson and Gavelin, 2000; Mair and Whitten, 2000; Roine et al., 2001). Others note that such moves may change the nature of health services and the practice of medicine, resulting, for example, in a medicalisation of essentially social questions (Fisk, 1995; Gott, 1995).

\footnotetext{
${ }^{1}$ http://www.doh.gov.uk/newsdesk/inside/may2002/index.html Last accessed 08/09/02.
} 


\section{CASE STUDY OF TELEHEALTH IN LEWISHAM}

The case study presented here, informed by interpretative and critical research modes, was conducted in 1998-2000 in the London Borough of Lewisham, a poor Borough in the south east of the city. A variety of data collection techniques were used, mostly un-structured interviews and when possible direct observation. Analysis of documentary sources offered different (generally official) viewpoints, additional details and background information. A number of councillors (elected politicians) and local government staff were interviewed about social development policies, IT strategies and their relation to national policies, as well as commitment to health related projects. Public forums organised to discuss issues of health, ICT and local needs, as well as local and national workshops and project specific meetings were attended. Following these meetings the researcher made contact with participants and subsequently was able to interview them and other people they suggested. In total 43 people were interviewed. The main themes discussed included the role of ICT in the provision of healthcare, local telehealth projects and initiatives, and the relationship between local strategies and national health policy. As a part of a larger study, the research data (documents, transcribed interviews and notes) were analysed from different perspectives using a broadly hermeneutic approach. In other work we have focused on an institutionalist perspective (KlecunDabrowska and Cornford, 2002), critical approach (Klecun-Dabrowska, 2003) and enacted technology (Cornford and Klecun-Dabrowska, 2001). This paper focuses on an analysis through social exclusion concepts.

Discussion with a variety of stakeholders who had institutional positions in healthcare and the local council revealed them as envisaging ICT as having an increasingly important role in enabling the delivery of services and changing the means of communication with citizens. This vision had led to the local council embarking on a Connected Community programme to harness ICT for the benefits of the community; in their terms, to regenerate it, to improve learning, employability and social inclusion, as well as to simplify government and strengthen democratic processes. For health and social care the Connected Community report (LBL, 1998) proposed, in partnership with community groups and health agencies, to enable people to engage with local clubs and voluntary groups through online connections, provide online community safety and health information, and offer support to homebound or fragile people, for example through Linkline facilities to emergency services, or by providing 'smart homes'. The programme was translated into concrete initiatives including the provision of terminals in libraries with free access to email and the Internet, multimedia kiosks in different locations including shops and pubs, and providing personal 
computers to schools, while IT skills were taught at local libraries and colleges. Other initiatives, included TellyTalk, One-Stop-Shop's and a community Intranet ${ }^{2}$. A One-Stop-Shop offers integrated and easy to access to multiple services at one point of contact, while TellyTalk is a free videoconferencing facility to connect people to local and national service providers ${ }^{3}$.

Aiming to involve the community in shaping such local services (or being seen to do so) the Council organised a number of open one-day meetings. One of these, the Connected Community Forum provided an arena for discussions and workshops on how ICT could benefit people. This focus on technology rather than wider initiatives impelled one of the participants to ask: "Why are we talking so much about information technology?" Nevertheless, the Forum, did discuss many relevant issues including social cohesion and education, and was not overtly technologically deterministic, perhaps because local people from different professions, groups and ages led it. A number of initiatives were put forward, including re-designing Lewisham web-pages to centre them around local residents' needs rather than those of potential visitors and developing a degree of interactivity with links to local information and community projects. Other initiatives emerged and action groups were set up to work on different projects, not necessarily involving ICT, e.g. providing support to the elderly through home visits.

During one of the Forum workshops telehealth's potential to improve access to healthcare was the theme. Suggested services included televisits at home and teleconsultations in GP surgeries or local clinics and were seen as serving the socially excluded (either by their illness or fragility or by having little money to travel). It was also suggested that telehealth could offer busy people access to health advice outside their working hours (for example through NHS Direct or PolyClinics). Participants did express concerns about who would be able to take advantage of new digital services, recognising that while initiatives aiming to strengthen social inclusion and close the digital divide existed, focus on digital services could divert attention from other more valuable initiatives. The second Forum focused directly on health and healthcare. Here ICT played a small part in the local residents' vision of how the health of the local population might be improved. Instead, the participants established their sense of a clear link between health, health services and the local environment, demonstrating the necessity to retain a holistic understanding of community needs rather than isolated services.

Another initiative under the Institute Of Health Services Management (IHMS) Telemedicine and Telecare programme brought together

\footnotetext{
${ }^{2}$ see www.lewisham-visibledifference.org.uk Last accessed 29/10/2002

${ }^{3}$ see http://www.lewisham.gov.uk/NewsAndViews/tellytalk.asp Last accessed 29/10/2002
} 
representatives of social services, health organisations and patients. The aim was to identify key healthcare related needs in Deptford (probably the most deprived area of Lewisham), discuss issues and problems facing health and social support services, and to explore the potential of ICT. Three broad aims were identified: enabling and supporting self-care, promoting interagency working, and improving efficiency. For each of these a number of potential ICT-based applications were identified and relevant services included Electronic Health Records, electronic referrals, more teleconferencing and teleconsultations between different health and care providers, and Internet-based information and training.

Taken all together we see wide-ranging needs expressed by citizens and healthcare providers, and a general ability to suggest possible ICT-based services that might help to address them, including dimensions of availability and accessibility as identified above. But ICTs were still largely seen as (fairly) unproblematic and such benefits were considered as either already proven in other settings or as just requiring further assessment. Little doubt was expressed about the viability of proposals while an integrated, 'strategic' approach and multi-use of equipment and resources was often proposed in order to reap benefits and reduce costs.

This programme of consultation, not withstanding its limitations, produced valuable suggestions regarding potential application areas for telehealth in Lewisham. It gave healthcare and social workers an opportunity to learn about ICTs, as well as to discuss potential reforms to the way their own services were run. It also provided a (limited) forum for citizens and patients to voice their opinions, and the approach of the workshops did encourage looking at contextualised problems first, rather than finding technological solutions. While the outcomes may appear to be 'wish lists', they did correspond quite closely with the national policy agenda $(\mathrm{DOH}$, 2000; DOH, 2002; NHS Executive, 1998). Indeed, at the time many individual projects were under way in the Borough, including for example, a telepsychiatry service allowing consultations to take place in a family doctor's practice linked to a hospital-based consultant via teleconferencing equipment (McLaren et al., 1999). This project was described by the Development Manager at the Community Mental Health Trust as a part of a wider strategy: "We feel that we have a way of revolutionising the delivery of health care, making it more accessible and immediate. And particularly for disadvantaged communities, they may not have access to expert care - a way of bringing it to them". Yet one of the project's originators admitted: "We are not at all convinced that we are adding value". Another local project, Deptford's Women and Children's Centre, was an early pregnancy assessment unit in a very deprived neighbourhood with a telemedicine link for ultrasound scans and teleconferencing to hospital consultants. 
Interestingly this telemedicine link was never used and was finally disconnected. However, the centre itself, although perhaps not effective in narrow cost terms, was popular locally and was seen as achieving its aim of providing new services and increased access to healthcare for a vulnerable group.

Two other indicative projects utilised the Web. EmpowerNet, offered information and limited interactive services for people with mental health problems and was developed by them as part of vocational training in web design. This project was given a clinical role, as the Director of the Community Mental Health Trust put it, "It is really important being honest with people about what information we have or don't have about the illness, effectiveness of treatment and about side effects. [...]And people find that very challenging because everyone always wanted to say that psychiatry is a science and it isn't". The SeaHorse project explored the potential of ICT for supporting people with HIV/AIDS and facilitating collaboration between carers (Cullen, 1997). This included assessment of information needs of selfhelp groups and development of computer-based applications, including interactive services and decision support tools, as part of a larger European funded project with partners from different countries. One of this projects co-ordinators emphasised its inclusionary potential: "Because we are offering services at home, we give access to information which otherwise the users wouldn't get if they weren' $t$ ' well enough to get to a library or if they weren't earning enough money to have their own Internet connection.".

While most professional people interviewed - those involved in these projects and those working in local government - were enthusiastic about new technologies or at least believed that their potential could be harnessed to benefit citizens, some voiced concerns. For example, they worried that services may become depersonalised (e.g. caring aspects being replaced by technical intervention, leading to medicalisation of care), or be of lesser quality (e.g. provided by staff without adequate training in the use of a particular technology), and that patients might loose confidence in the services. As one interviewee noted, "I think we are giving people power to choose not to go to a doctor. I'm not certain that's actually good. [...] They would say 'but the user is in control because they can press the button'. But they don't want to press a button, they want help". A social worker too expressed uneasiness about sharing data between social and health services, foreseeing people withdrawing some information they would otherwise pass on to healthcare workers. She also questioned the viability of using teleconferencing equipment to communicate with the elderly and patients with hearing or sight problems and who find it difficult enough to use a telephone. More generally many staff felt unsure how to best utilise ICT and 
what the future would brings for them, “... we are moving too fast and some people will be left behind".

\section{DISCUSSION}

Social exclusion is a dynamic process, effecting different people in different ways at different points of time. Here we consider what this implies for ICT as a constitutive element of healthcare within a community - what sort of services it implies. Our understanding of social exclusion leads us to a paradox; that services supported by technology need to be both targeted and broad; meet individual needs but also foster positive community processes that promote use. One route is for these groups to be actively engaged in the design of the services (as in EmpowerNet). At the same time such services need to cater for people's changing circumstances over time. Conceptualising social exclusion as the interplay of multi-dimensional processes suggests that ICT-based health initiatives should focus less on consequences of exclusion, but rather on process that lead to it. For example, if the manifestation of social exclusion is through ill health related to poor diet and low income we may try to promote healthy eating, for example in schools, and offer skills training. Still, simply adding web-based information to this mix is unlikely to prove a powerful additional force unless it too is linked back into other community resources. As Milio (1992) points out, the value of health information goes beyond creating individual awareness to include educating and motivating for action. When shared (in two-way exchange), she suggests, it can also help to express and test ideas, bind people and communities and foster an environment conductive to well being.

In this case study we see national and local policies, new technologies and 'bottom-up' initiatives being translated into projects that attempted to use ICT to bring health and social services closer to people and their communities, to make them more 'customer-centred' and to provide support for self-help activities. Both central and local government sees such initiatives as linked and mutually reinforcing, evoking the concepts of 'joined-up thinking' and a multi-deprivation perspective on social exclusion. The Local Authority thus had policies based around ICT that aimed to address social exclusion by aiming at the 'regeneration' of the local community. The Forums indicate that local people see health, education and the environment as inter-connected, and ICT as playing a part in supporting social inclusion rather than having a central role. Similarly, the four projects briefly outlined illustrate the diversity of issues and multiple facets of exclusion that were being addressed in terms of different groups of socially excluded- the chronically ill, their carers, or a vulnerable population - but 
also in terms of the size and scope of projects and the technologies applied. Similarly, the extent to which they were shaped by local people varied considerably. What they share is an assumption that making service delivery local benefits the population; that it helps to target at local needs, gains the community's support, and can alleviate inequalities. This also reflects a more holistic approach to health, one that takes into account social and personal circumstances on health and addresses stress and stigma, as well as family and financial consequences, and the potential for peer support.

However, this research also indicates some problems encountered in addressing social exclusion through ICT. Critiques of the Lewisham policy documents (Sullivan, 1998; Sullivan and Quirk, 2000) suggest that they offer a simplistic portrayal of ICT-based reforms and unquestioning ascription to ICT of qualitative transformational potentials (Klecun-Dabrowska, 2002). A report assessing the Connected Community initiative highlights the unequal spread of resources that privilege some deprived areas over others - those with allocated special funds (Forbes, 2001). Many innovative ICT-based projects struggle during implementation and find it hard to sustain themselves once special funding is withdrawn. Equally expectations may be raised which may not be fulfilled, and while ICT have the potential to help to overcome some forms of exclusion, they may also create new forms or reinforce existing ones. The experience of the Deptford's Women and Children's Centre indicates that new technologies are not always needed and re-designing work practices or models of care delivery may be more beneficial. As Silverstone and Haddon (1998) suggest "While any benefits offered by new telematics may be welcomed, the new options and possibilities these technologies bring simultaneously mean that the mechanisms and nature of deprivation or inequality - what resources, competencies and cultural values are involved - are in a constant process of change." They note in particular the closing down of opportunities for interaction, involvement and the ability to influence ones environment through participation in political/economic life.

While in the initiatives we study here community involvement goes some way towards containing (if not reducing) such an emerging digital divide, as Van Dijk and Hacker (2000) (referenced in Kvasny and Truex (2001)) argue, structural forces beyond the physical access to technology act to perpetuate the divide, and increased material access may not necessarily lead to decreased structural divides. One dystopian vision of ICT in the UKs NHS is as providing an alternative to the established services, or as a 'fast track' that might undermine - not re-enforce - the inclusionary ethos. We also see some more specific dimensions of exclusion actually or potentially at work and enhanced through ICT in the allocation of scarce resources and acceptance of opportunity costs, and in the medicalisation of care. Although 
projects such as SeaHorse focus specifically on empowering socially excluded groups, they may also serve to increase the isolation of their target communities if they do not promote a sense of involvement in the wider community. For carers too the solidarity they can develop, or the sense of power they feel in decision-making, may come to reinforce their isolation. In summary, health services delivered through ICT, particularly personal telecare systems, might positively contribute to social isolation and be exaggerated by displacement of other relationships. For example, substitution of day centres, where older or disabled people meet and engage in varied activities, by discussion groups over the Internet, or the substitution of a visit to Grandma with a call to the call centre to receive a report on her vital signs and her mobility index in the past 24 hours.

\section{CONCLUSIONS}

How to deploy ICT to reform and restructure the delivery of care in order to achieve better, more equitable healthcare is a wide spread concern for communities, governments and international organisations as they struggle to define (and enact) new conceptions of citizenship and belonging within an illusive 'global information society'. This paper has set out to consider these issues and to present community view(s) on ICT-supported health services through a social exclusion perspective. Social exclusion, as we argue in the introduction, provides a robust and theoretically sound basis for such analysis and the paper seeks to add to the qualitative based empirical work in a field where the weight of literature is either theoretical or based on statistical analysis.

We argue here that the relationship between information systems, health services and social exclusion is complex, and cannot be approached through a narrow understanding of access (access to ICT and access to health services). Thus, section 2 develops descriptions of different dimensions of social exclusion in health and relates them to the potentials of ICT as seen in the IS literature. Our study suggests that ICT-based services are seen as potentially benefiting the community, but there is a strong concern that this must not lead to further exclusion of some groups. The Forum meetings and workshops often suggested that such services should be provided in addition to conventional ones, and initiatives should be based on active participation of community members. Our interviews also indicate that some health and social workers themselves feel excluded by technology and are afraid of being 'passed by'. Finally, both the Forums and workshops saw the potential of information systems and ICT-based services only as part of and within a wider program of regeneration and reform of health service. The indicative 
projects we describe (telepsychiatry, telelink at the Deptford Centre, SeaHorse and EmpowerNet) show that such initiatives do have potential to address some dimensions of exclusion (e.g. distance, time and awareness), but they may have little effect on agency aspects if not embedded in local contexts and institutions, and receiving long-term support.

We suggest that viewing ICT through the social exclusion perspective helps us to go beyond medical, technological or even organisational frameworks and to link to concepts of citizenship and belonging in an Information Society. Still, in this paper, we have told an incomplete story. We have no space here to discuss the different and often ambiguous meanings that ICT acquire in policy and strategy, and the meanings that are forged during the development, implementation and use of each such service. To do so we would have to draw explicitly on the more substantial theoretical approach of critical theorists (Feenberg, 1991; Habermas, 1979; Horkheimer and Adorno, 1972 [1944]), where social exclusion can embody one dimension of a critical study of ICT. But then it would another paper.....

\section{REFERENCES}

Andersen, J. "Social and System Integration and the Underclass", In Capitalism and Social Cohesion: Essays on Exclusion and Integration, I. Gough and G. Olofsson (Ed.), London: Macmillan, 1999, pp. 127-148.

Atkinson, T. "Social Exclusion, Poverty and Unemployment", London School of Economics, Centre for Analysis of Social Exclusion, 1998.

Avgerou, C. Information Systems and Organizational Diversity: The Articulation of Local and Global Rationalities, Oxford: OUP, 2002.

Brennan, P.F., Schneider, S.J. and Tornquist, E. (Ed.) Information Networks for Community Health, New York: Springer-Verlag, 1997.

Burchardt, T., Grand, J.L. and Piachaud, D. "Social Exclusion in Britain 1991-1995", Social Policy and Administration, (33:3), 1999, pp. 227-244.

Burchart, T., Le Grand, J. and Piachaud, D. "Introduction", In Understanding Social Exclusion, J. Hills, J. Le Grand and D. Piachaud (Ed.), Oxford: OUP, 2002, pp. 1-12.

Collins, K., Nicolson, P. and Bowns, I. "Patient Satisfaction in Telemedicine", Health Informatics Journal, (6), 2000, pp. 81-85.

Compaine, B.M. (Ed.) The Digital Divide. Facing a Crisis or Creating a Myth?, Cambridge, Ma.: MIT Press, 2001.

Cornford, T. and Klecun-Dabrowska, E. "Telehealth Technology: Consequences for Structure through Use", Proceedings of the 10th World Congress on Medical Informatics, London, 2001

Coyle, G., Boydell, L. and Brown, L. "Home Telecare for the Elderly", Journal of Telemedicine and Telecare, (1), 1995, pp. 183-184.

Cullen, J. "Final Report on the Feasibility of SEAHORSE", Telematics Application Programme (EC DGXIII); Project: HC 1111; SEAHORSE Support and empowerment for AIDS and HIV: the on-line research and self-help exchange, February 1997. 
DHSS "Inequalities in Health: The Black Report", Department of Health and Social Services, London, 1980.

DOH "Our Healthier Nation: A Contract for Health", HMSO, London, 1998.

DOH "Saving Lives: Our Healthier Nation”, HMSO, London, 1999.

DOH "The NHS Plan -The Command Paper 4818-1", HMSO, London, July 2000.

DOH "Delivering the 21 st Century IT Support for the NHS: National Strategic Programme", Department of Health, 2002.

Dutton, W.H. and Peltu, M. (Ed.) Information and Communication Technologies: Visions and Realities, Oxford: OUP, 1996.

Feenberg, A. Critical Theory of Technology, New York: Oxford University Press, 1991.

Fisk, M.J. "A Comparison of Personal Response Services in Canada and the UK", Journal of Telemedicine and Telecare, (1:3), 1995, pp. 145-156.

Forbes, M. "Implementing a Connected Community Strategy for Lewisham: A Framework for Action”, Doc Ver. 2.0, London Borough of Lewisham, 2001.

Gore, C. and Figueiredo, J. (Ed.) Social Exclusion and Anti-Poverty Policy: A Debate, Geneva: ILO, 1998.

Gott, M. Telematics for Health: The Role of Telehealth and Telemedicine in Home and Communities, Oxford: Radcliffe Medical Press, 1995.

Gustafson, D.H., Hawkins, R.P., Boberg, E.W., et al. "CHESS: Ten Years of Research and Development in Consumer Health Informatics for Broad Populations, Including the Underserved", Proceedings of the 10th World Congress on Medical Informatics, London, 2001, pp. 1459-1463.

Habermas, J. Communication and the Evolution of Society, Boston: Beacon Press, 1979.

Haddon, L. "Social Exclusion and Information and Communication Technologies", New Media and Society, (2:4), 2000, pp. 387-406.

Hakansson, S. and Gavelin, C. "What do we Really Know About the Cost-Effectiveness of Telemedicine?," Journal of Telemedicine and Telecare, (6:1), 2000, pp. S1:133-136.

Heeks, R., Mundy, D. and Salazar, A. "Information Systems for Public Sector Management", Working paper 9, Institute for Development Policy and Management, Manchester, 1999.

Hills, J. “A CASE for Investigation”, LSE Magazine (Winter), 1997, pp. 7-9.

Hills, J., Le Grand, J. and Piachaud, D. (Ed.) Understanding Social Exclusion, Oxford: OUP, 2002.

Horkheimer, M. and Adorno, T.W. Dialectic of Enlightenment, New York: Herder, 1972 [1944].

Klecun-Dabrowska, E. "Telehealth and Information Society: a Critical Study of Emerging Concepts in Policy and Practice", London School of Economics and Political Science, 2002.

Klecun-Dabrowska, E. "Telehealth in the UK: a Critical Perspective", Proceedings of the 2nd European Conference on Research Methodology for Business and Management Studies, Reading, UK, 2003,

Klecun-Dabrowska, E. and Cornford, T. "Organising vision of telehealth," Proceedings of the 10th European Conference on Information Systems, Gdansk, Poland, 2002, pp. 12061217.

Kling, R. "Beyond Outlaws, Hackers, and Pirates: Ethical Issues in the Work of Information and Computer Science Professionals", In Computerization and Controversy: Value Conflicts and Social Choices, R. Kling (Ed.), San Diego: Academic Press, 1996.

Kvasny, L. and Truex, D. "Defining Away the Digital Divide: A Content Analysis of Institutional Influences on Popular Presentations of Technology", Proceedings of the IFIP Working Group 8.2, Boise, Idaho, USA, 2001, 
LBL "Connected Community", London Borough of Lewisham, Policy and Resources Committee, London, 1998.

Mair, F. and Whitten, P. "Systematic Review of Studies of Patient Satisfaction with Telemedicine", British Medical Journal, (320:7248), 2000, pp. 1517-1520.

McLaren, P., Mohammedali, A., Riley, A., et al. "Integrating Interactive Television-Based Psychiatric Consultation into an Urban Community Mental Health Service", Journal of Telemedicine and Telecare, (5:1), 1999, pp. S1:100 - 102.

Milbourne, L. "Unspoken Exclusion: Experiences of Continued Marginalisation from Education Among 'Hard to Reach' Groups of Adults and Children in the UK", British Journal of Sociology of Education, (23:2), 2002, pp. 287-305.

Milio, N. "New Tools for Community Involvement in Health", Health Promotion International, (7:3), 1992, pp. 209-217.

NHS Executive "Information for Health: An Information Strategy for the Modern NHS 19982005”, Leeds, 1998.

Norris, P. Digital Divide: Civic Engagement, Information Poverty and the Internet Worldwide, Cambridge: Cambridge University Press, 2001.

Phipps, L. "New Communications Technologies: A Conduit for Social Inclusion", Information, Communication \& Society, (3:1), 2000, pp. 39-68.

Richardson, L. and Grand, J.L. "Outsider and Insider Expertise: The Response of Residents of Deprived Neighbourhoods to an Academic Definition of Social Exclusion", London School of School of Economics, Centre for Analysis of Social Exclusion, 2002.

Roine, R., Ohinmaa, A. and Hailey, D. "Assessing Telemedicine: A Systematic Review of the Literature", Canadian Medical Association Journal, (165:6), 2001, pp. 765-71.

SEU "So you Would Like to Know More", Social Exclusion Unit, Cabinet Office 1999. Last Accessed 10 February 2003, http://www.cabinet-office.gov.uk/seu/index/mre.html

Silverstone, R. and Haddon, L. "New Dimension of Social Exclusion in a Telematic Society, Working paper 45", Graduate Research Centre for Culture and Communication (CULCOM), University of Sussex 1998.

Sixsmith, A.J. "An Evaluation of an Intelligent Home Monitoring System", Journal of Telemedicine and Telecare, (6), 2000, pp. 63-72.

Sosa-Iudicissa, M., Oliveri, N., Gamboa, C.A., et al. (Ed.) Internet, Telematics and Health, Amsterdam, Berlin, Oxford, Tokyo, Washington, DC: IOS Press, 1997.

Sullivan, D. "Modernising Lewisham", London Borough of Lewisham, London, 1998.

Sullivan, D. and Quirk, B. "Where its @: Lewisham's Strategy for Getting Connected", London Borough of Lewisham, February 2000.

Van Dijk, J. and Hacker, K. "The Digital Divide as a Complex and Dynamic Phenomenon", Proceedings of the International Communication Association, Acupulco, Mexico, 2000,

Warner, I. "Telemedicine Applications for Home Health Care", Journal of Telemedicine and Telecare, (3:1), 1997, pp. S65-S66.

Whitten, P., Collins, B. and Mair, F. "Nurse and Patient Reactions to a Developmental Home Telecare System", Journal of Telemedicine and Telecare, (4), 1998, pp. 152-160.

Yach, D. "Telecommunications for Health - New Opportunities for Action", Health Promotion International, (13:4), 1998, pp. 339-347. 


\section{About the Authors}

Tony Cornford is a senior lecturer in Information Systems at the London School of Economics and Political Science. He graduated in Economics, obtained a Masters degree in operational research and a $\mathrm{PhD}$ in information systems, all from the LSE. His research interests include the dubious concept of implementation. Tony can be reached by e-mail at t.cornford@1se.ac.uk. or through his home page at http://is.lse.ac.uk/staff/ cornford

Ela Klecun-Dabrowska is a lecturer in Information Systems at the London School of Economics and Political Science. She was born in Warsaw, Poland where she obtained her matura. She completed her first degree, masters degree and $\mathrm{PhD}$ in the UK. She holds a $\mathrm{PhD}$ in the area of telehealth from the London School of Economics. Her research interests include health information systems and telehealth, evaluation of information systems, and the application of critical theory in the field of information systems. Ela can be reached by e-mail at e.Klecun@lse.ac.uk 